\title{
An investigation into the psychometric properties of the CORE-OM in patients with eating disorders
}

Article

Accepted Version

Jenkins, P. E. and Turner, H. M. (2014) An investigation into the psychometric properties of the CORE-OM in patients with eating disorders. Counselling and Psychotherapy Research, 14 (2). pp. 102-110. ISSN 1473-3145 doi:

https://doi.org/10.1080/14733145.2013.782057 Available at https://centaur.reading.ac.uk/76096/

It is advisable to refer to the publisher's version if you intend to cite from the work. See Guidance on citing.

Published version at: http://dx.doi.org/10.1080/14733145.2013.782057

To link to this article DOI: http://dx.doi.org/10.1080/14733145.2013.782057

Publisher: Wiley

All outputs in CentAUR are protected by Intellectual Property Rights law, including copyright law. Copyright and IPR is retained by the creators or other copyright holders. Terms and conditions for use of this material are defined in the End User Agreement.

www.reading.ac.uk/centaur 
Central Archive at the University of Reading

Reading's research outputs online 


\title{
An investigation into the psychometric properties of the CORE-OM in patients with eating disorders
}

\begin{abstract}
Aim: The current study aimed to explore the psychometric properties of the CORE-OM (Clinical Outcomes in Routine Evaluation - Outcome Measure) when used in an eating disorder sample. Method: The CORE-OM was administered at assessment to 360 consecutive referrals to an eating disorders service. Principal component analysis was conducted to look at the psychometric structure of the CORE-OM, and psychometric properties were investigated using analyses of reliability and validity. Results: Analyses of the psychometric structure suggested a three-component solution reflecting negatively worded, positively worded and risk items. The CORE-OM showed good acceptability, acceptable internal and test-retest reliabilities, as well as good convergent and known groups validity. Conclusions: The results of the current study support the CORE-OM as a reliable and valid measure for assessing psychological distress in eating disorders.
\end{abstract}

Keywords:

Outcome Measure; CORE-OM; Eating Disorders; Validation 
The Clinical Outcomes in Routine Evaluation Outcome Measure (CORE-OM; Barkham et al., 2001; Evans et al., 2002) is a self-report questionnaire designed to measure general psychological distress, including an assessment of risk, in those presenting for psychological therapy. It can be used to assess differences between individuals in terms of their level of distress, and can also be used as a measure of individual change over time, and hence clinical effectiveness. The CORE-OM consists of 34 items covering the following four dimensions: subjective well-being; problems; functioning; and risk. Psychometric validation studies have reported good reliability ratings, with internal consistency for the subscales ranging from 0.75-0.94 (Evans et al., 2002; Barkham et al., 2005a). Acceptability of the measure has also been reported as good, with high completion rates; $80-90 \%$ of individuals complete the measure, with around $98 \%$ of questionnaires providing sufficient data for analysis (e.g., Barkham et al., 2005a). In terms of the structure of the measure, a four-subscale scoring matrix was originally proposed (Barkham et al., 2001; see also Uji, Sakamoto, Adachi, \& Kitamura, 2012), and a three-component model has also been suggested (Evans et al., 2002). In a large study $(N=2,140)$ testing a number of hypothesised models, a two-component solution, assessing risk and psychological distress, was identified as having a good fit with the data (Lyne, Barrett, Evans, \& Barkham, 2006).

To date, the CORE-OM has been used as an effective measure in a wide range of settings, including primary and secondary NHS services, as well as within occupational health, school, and university settings (e.g., Barkham et al., 2005a; Barkham et al., 2006; Killips, Cooper, Freire, \& McGinnis, 2012; see also http:// www.coreims.co.uk/Downloads_References.html for a list of studies). Research also suggests that the CORE-OM is acceptable to clients engaged in psychological therapy 
(Barkham et al., 2005b; Cahill et al., 2006), and thus it has become a widely used outcome measure in mental health settings across the UK (Bedford et al., 2010). It has 'copyleft' status, meaning that it is free to use for not-for-profit purposes, and therefore has benefit in assessment and outcome measurement in a nationalised health service (e.g., Bewick, Trusler, Mullin, Grant, \& Mothersole, 2006). It is a brief measure that can provide standardised responses across a range of treatments and conditions, designed to replace the wide number of different outcome measures that are often used. The provision for the assessment of risk gives clinical indicators for clinicians to explore further.

The assessment of functional impairment and global distress in eating disorders (EDs) is growing in importance as a key assessment and outcome measure (Jenkins, Hoste, Meyer, \& Blissett, 2011). However, whilst a range of measures have been developed to assess ED pathology (e.g., EDE-Q, Fairburn \& Beglin, 1994), and functional impairment secondary to ED symptoms (e.g., CIA; Bohn \& Fairburn, 2008), there exist few measures assessing general psychological distress that have been validated for use in eating disorders. It is possible that the CORE-OM might represent a useful measure of psychological distress in this patient group that not only complements existing symptom-specific measures, but also provides a useful measure of clinical effectiveness.

The CORE-OM has been previously used in treatment studies of EDs (e.g., Traviss, Heywood-Everett, \& Hill, 2011) and an association between eating disorder severity and impairment (as reported on the CORE-OM) has been found for individuals with EDs (e.g., Barkham et al., 2005a; Wright, Bewick, Barkham, House, \& Hill, 2009). Other studies (e.g., Hoffart, Lysebo, Sommerfeldt, \& Rø, 2010; Traviss et al., 2011; 
Simpson \& Slowey, 2011) have used the CORE-OM, or a subset of items derived from the measure, to assess outcome. However, despite recent use of the CORE-OM as a marker of impairment in some recent studies of eating disorders, it is not yet known whether this is a reliable and valid measure for use within the eating disorders field. In light of the unique nature of the impairment caused by the central characteristics of the disorder (Bohn et al., 2008) it is possible that patients with ED might demonstrate markedly higher or lower internal consistency and a different pattern of results from exploratory component analysis compared with other samples (e.g., Evans et al., 2002; Lyne et al., 2006) and this possibility will be explored by investigating whether the CORE-OM demonstrates similar psychometric properties in an ED sample compared to other clinical samples. The paper also aims to look at the acceptability of the CORE$\mathrm{OM}$, as well as provide estimates of internal reliability, test re-test reliability, convergent validity and known groups validity. Furthermore, variations associated with gender and ED diagnosis will also be investigated.

\section{Method}

\section{Participants and Procedure}

Participants were 360 referrals to a specialist adult community ED service over a threeyear period. As part of routine clinical care, patients attending an initial assessment appointment at the ED service are asked to complete a number of self-report questionnaires, including those used in the present study. In addition, the Eating Disorder Examination (EDE; Fairburn \& Cooper, 1993) is administered by clinicians trained in its use. The protocol was reviewed by the local NHS Trust Research and 
Development Team and was deemed to constitute an audit of the measures routinely used in clinical practice.

\section{Measures}

\section{Sociodemographic Information}

Information related to age, gender, and ethnicity was obtained from a demographic questionnaire routinely given to patients as part of their assessment.

The Clinical Outcomes in Routine Evaluation Outcome Measure (CORE-OM; Barkham et al., 2001)

The CORE-OM is a self-report measure of overall functioning, comprised of 34 items relating to symptoms experienced over the last week rated on a 5-point frequency scale ranging from 0 ('not at all') to 4 ('most or all of the time'), with higher scores indicating more problems. The CORE-OM also has subscales (domains) of subjective well-being (4 items), problems (12 items), and functioning (12 items), as well as a further domain assessing risk (6 items). Total and domain scores are calculated by summing scores of all those items that were completed, and dividing by the number of items completed. A total minus risk score can also be generated by summing the means of the domain scores (excluding risk), also labelled 'psychological distress' (Lyne et al., 2006). Following the suggestions of Evans et al. (2002), domain scores were pro-rated where only one item was missing. If more than three items of the total (i.e., of 34 items) had been omitted by a participant on the measure, scores were not pro-rated, designated as 'incomplete,' and excluded from subsequent analysis. Using this method, acceptability of the measure is generally high. Reported reliability ratings are generally good (see 
above), with a number of validation studies supporting use of the CORE-OM in its original language, and also translated versions (e.g., Elfström et al., in press).

The Eating Disorder Examination (EDE; Fairburn \& Cooper, 1993)

The EDE is an investigator-led interview widely used in the assessment of eating disorder psychopathology. The EDE generates the following four subscales: Dietary Restraint; Weight Concern; Shape Concern; and Eating Concern. Subscale ratings consist of frequency scores (0-6) and severity scores (0-6). The EDE also gathers information relating to the frequency of key eating disorder behaviours (e.g., binge eating, self-induced vomiting, laxative misuse, and driven exercise) and can be used to generate operationally defined DSM-IV eating disorder diagnoses. This interview has been refined over the years in order to improve its reliability and validity, with psychometric properties assessed in a number of studies. Alpha coefficients for subscale scores have been reported as ranging from .97 and .99 (Wilson \& Smith, 1989). The EDE also has good discriminant (Wilson \& Smith, 1989) and concurrent validity (Rosen, Vara, Wendt, \& Leitenberg, 1990). It is widely regarded as the diagnostic 'gold standard' in eating disorders research and is suitable for use in community and clinical populations. The most up-to-date version of this instrument, EDE 16.0, is used by the service. As part of the EDE, weight was measured to the nearest $0.1 \mathrm{~kg}$ using digital scales that were calibrated every 6 months and height was measured to the nearest centimeter using a stadiometer. These measurements were used to calculate Body Mass Index (BMI; weight $(\mathrm{kgs}) /$ height $\left.(\mathrm{m})^{2}\right)$. Cronbach's $\alpha$ for the Global EDE score was 0.85 . 
The Clinical Impairment Assessment (CIA; Bohn \& Fairburn, 2008)

The CIA is a 16-item self-report measure of functional impairment occurring secondarily to eating disorder symptoms. Higher scores denote greater functional impairment, with items rated on how much they have interfered with functioning over the last 28 days on a scale of 0 ("Not at all") to 3 ("A lot"). Subscale scores can be computed, and an overall total score can be calculated (used in the current study) by summing the scores on all items (i.e., maximum total $=48$ ). Preliminary studies support the psychometric properties of the CIA for assessing impairment resulting from ED symptoms (e.g., Bohn et al., 2008). Cronbach's $\alpha$ for the CIA Total score was 0.91 .

The Hospital Anxiety and Depression Scale (HADS; Zigmond \& Snaith, 1983)

The HADS is a 14-item self report measure that can generate subscales giving an index of depression (HADS-D) and anxiety (HADS-A) symptoms over the past week. Responses are provided on a 4-point (0-3) scale, providing a possible total score of 21 for each subscale. It is widely used with good internal reliability (Crawford, Henry, Crombie, \& Taylor, 2001) as well as good test-retest reliability (Spinhoven et al., 1997), and its use has been supported in a number of different samples (e.g., Bjelland, Dahl, Haug, \& Neckelmann, 2002; Mykletun, Stordal, \& Dahl, 2001; Snaith, 2003).

\section{Data screening and Statistical Analysis}

Prior to analysis, responses on all questionnaires were tabulated, and then descriptive statistics used to identify extreme values which may indicate data entry errors. Principal component analysis was carried out to investigate the psychometric structure of the CORE-OM, retaining items that loaded above .4 as this is often considered 
suitable (Sheffield \& Lemétayer, in press; Stevens, 2002). Subscale and total scores for the CORE-OM were non-normally distributed (Shapiro-Wilk $p$ s $<.05$ ), and therefore nonparametric tests were used where possible (Evans et al., 2002). Cronbach's $\alpha$ was employed as an estimate of internal consistency reliability. Test-retest reliabilities were computed on a subset of participants who started treatment following assessment who had been waiting between 1-12 weeks $(n=33)$. Where possible, estimates of confidence intervals (CIs) for mean differences are provided to reflect a more meaningful interpretation of group comparisons. Given that the data were largely nonnormally distributed, parametric CIs are reported although it should be cautioned that this violates the assumption of normality; however, it is unlikely that this will have caused the CIs to be very misleading. Analyses were conducted using SPSS version 19.0.

\section{Results}

\section{Sample characteristics}

Mean age was 27.6 years $(\mathrm{SD}=9.4$, range $=17-67$, median $=25.0,95 \%$ CIs $26.5-$ 28.6) and $338\left(93.9 \%\right.$ ) were female. Mean body mass index (BMI) was $21.8 \mathrm{~kg} / \mathrm{m}^{2}$ (SD $=6.6$, range $=12.0-61.9$, median $=20.0,95 \%$ CIs $=21.1-22.6)$. Two hundred and ninety one individuals described themselves as 'White British' (92.7\%), four (1.3\%) as 'White Irish', seven (2.2\%) as 'White - Other', three (1.0\%) as 'Asian/British', two $(0.6 \%)$ as 'Black/British', one $(0.3 \%)$ as 'Mixed heritage - White and Asian', and two $(0.6 \%)$ as 'Mixed heritage - Other', and one individual $(0.3 \%)$ indicated 'Any Other' Ethnic group. Forty-nine (13.6\%) did not provide data on their ethnicity. 332 (92.2\%) individuals were diagnosed with a clinical eating disorder; $28(7.8 \%)$ did not have an 
ED of clinical severity. Of those with an ED, 63 (19.0\%) received a diagnosis of anorexia nervosa (AN), 120 (36.1\%) were diagnosed with bulimia nervosa (BN), and $149(44.9 \%)$ as eating disorder not otherwise specified (EDNOS), using DSM-IV criteria (APA, 2000). Mean BMI for those in the AN group was 16.8, for those in the BN group 24.3, and for those in the EDNOS group 22.1.

\section{Gender differences in scores}

Results of Mann-Witney $U$ tests showed no statistically significant difference by gender of any of the scales of the CORE-OM ( $p s>.05)$. Group means and 95\% confidence intervals (CIs) are reported in Table 1.

Insert Table 1

\section{Diagnostic differences in scores}

Results of Kruskal-Wallis tests showed no significant difference between CORE scores by ED diagnosis ( $p s>.417)$.

\section{Acceptability}

The most frequently missed items on the CORE-OM were Item 33 ('I have felt humiliated or shamed by other people') and 21 ('I have been able to do most things I needed to'), with a total of 6 omissions each (1.7\%). There was also a clustering of missing data towards the end of the measure, suggesting that some people tend to fill in only page 1 (the measure is 2 -sided). The overall item omission rate in this sample was $0.77 \%(95 \% \mathrm{CI}=0.73-0.82 \%)$ and completion rates were fairly high, with $97.5 \%$ of respondents providing sufficient data (after pro-rating) to allow scoring. 


\section{Determining the optimal psychometric structure}

Kaiser-Meyer-Olkin Measure of Sampling Adequacy was high (.94) and Bartlett's test of sphericity was significant $(p<.001)$. Principal component analysis (PCA) was conducted using pairwise deletion for missing data and oblique (Promax) rotation as items were hypothesised to correlate. These analyses were carried out on individuals who fulfilled the criteria for pro-rating (see above). Following inspection of the scree plot, it was decided that a 3-component solution was the most appropriate, which explained $45 \%$ of the variance (see Figure 1).

\section{Insert Figure 1}

Item loadings for the final 3-component solution are presented in Table 2.

Insert Table 2

\section{Internal Structure}

Cronbach's $\alpha$ s for the CORE-OM subscale scores demonstrated acceptable internal reliability (see Table 3). Regarding inter-item correlations, which also offer a measure of internal structure, Clark and Watson (1995) suggest that the average correlations should be $0.15-0.50$. The only inter-item correlations falling outside of this range were for Items 6 ('I have been physically violent to others'; average inter-item correlation = 0.05 ) and 22 ('I have threatened or intimidated another person'; average correlation = $0.09)$.

Insert Table 3 


\section{Test-retest Reliability}

Using a subset of patients who had been waiting between 1-12 weeks $(n=33)$, Spearman's $r$ indicated that scores on the CORE-OM were stable across time; wellbeing $=.67 ;$ problems $=.87 ;$ functioning $=.77 ;$ risk $=.84 ;$ total minus risk $=.85 ;$ total $=$ $.88($ all $p \mathrm{~s}<.01)$.

\section{Convergent Validity}

Significant associations were found between the CORE-OM and measures of symptom severity. CORE-OM subscales were significantly correlated with the EDE Global score (see Table 4). Convergent validity was demonstrated with strong correlations between the CORE-OM and measures of depression, anxiety, and functional impairment (see Table 4), measures which are conceptually similar to the CORE-OM, suggestive of convergent validity.

\section{Insert Table 4}

\section{Known Groups Validity}

Mann Whitney $U$ tests were used to assess whether the CORE-OM subscale scores could discriminate between those who had a clinical ED $(n=332)$, and those who did not $(n=28)$. Results (see Table 5) indicated that all subscale scores were significantly higher in the ED group compared with the non-ED group $(p s<.05)$.

Insert Table 5 


\section{Discussion}

This study aimed to explore the psychometric structure and properties of the CORE-OM when used in an ED sample. The present study found that a three-component structure emerged from PCA. Whilst similar findings are reported by Evans et al. (2002), who reported psychometric properties in a sample of outpatients referred for psychological therapy and a further non-clinical sample, it is worth considering that broad measures of psychological distress, such as the CORE-OM, are seldom designed to produce replicable component matrices. The only item in the current study that did not uniformly load onto one dimension was item 33, which was split between Components 1 (negatively worded) and 3 (risk). The internal structure of the subscales of the CORE-OM was generally good, with good internal consistency and acceptable interitem correlations. However, the items that fell outside of the suggested range for interitem correlations (see Clark \& Watson, 1995) concerned items regarding violence to other people, which may be a reflection of the low prevalence of these behaviours in ED samples; these results are therefore more likely to be an artefact of the relative infrequency of these traits. The results of the present study may suggest some item redundancy (see also Bedford et al., 2010). Given that a number of variations on the battery of CORE measures exist (e.g., see Barkham et al., 2006; see also Barkham et al., 2010, which includes a discussion of the CORE-10 and CORE-5), future studies might consider whether alternative versions of the CORE-OM are as useful as the 34-item version described here.

The results indicate that the CORE-OM demonstrates good psychometric properties when used in an ED sample, with psychometric data similar to existing studies on other clinical samples (e.g., Evans et al., 2002). Although the proportion of 
men in the current study was small, data from these individuals was included to provide a sample that was representative of individuals seen in a typical ED service; these results should therefore be treated cautiously in terms of their applicability to males with EDs. In line with previous findings (Barkham et al., 2005a), the results suggest that the CORE-OM is psychometrically robust and useful in a specialist ED setting. It discriminates between those with an ED and those without, and demonstrates good internal consistency. It correlates well with a measure of ED symptoms, an ED-specific measure of functional impairment and measures of general psychiatric symptoms (see also Barkham et al., 2001). Missing item analysis also supported its use, with very few individuals in the current study providing insufficient responses. Comparison of scores with data from a student counselling service (Connell, Barkham, \& Mellor-Clark, 2007), who might be considered a less severely impaired sample, suggested that those with EDs scored higher on the CORE-OM subscales.

Test-retest reliability of the measure appeared good and comparable to previous studies (e.g., Evans et al., 2002), although the current study only used a subset of data. Further work might seek to replicate this in a larger sample taken at one point in time. As the data used in the current study was taken primarily from the initial assessment, the results are not necessarily generalisable to other points in treatment (e.g., follow-up), although existing studies suggest that the CORE-OM is stable and sensitive to change over time (Evans et al., 2002). Further studies might look at the responsiveness of the CORE-OM to change in eating disorder symptoms over time (e.g., following treatment). The findings of the present study broadly support the use of the CORE-OM with ED patients. As such, this measure might form a useful addition to existing measures that are either symptom-specific or concerned with symptom-related functional impairment. 
More specifically, the CORE-OM might constitute a useful measure of psychological distress that can be used to explore differences between ED sub-groups, as well evaluate clinical change over time, although future studies may look at change during treatment to confirm this. It is possible that the CORE-OM might also be usefully used to compare outcomes across service settings. The preliminary findings reported here suggest that the CORE-OM can reflect differences between groups (e.g., on diagnosis), although this area warrants further investigation.

The findings of the current study provide preliminary evidence for the acceptability, reliability, and validity of the CORE-OM, suggesting that it may be constitute a useful instrument for assessing general distress and risk in eating disorders. Future research might usefully seek to replicate and extend the current findings, particularly in relation to further assessment of test re-test reliability and the measure's ability to detect clinical change over time.

Competing interests: none 


\section{References}

American Psychiatric Association (2000). Diagnostic and Statistical Manual of Mental Disorders (4th ed., text revision) (DSM-IV-TR). Washington, DC: APA Press.

Barkham, M., Margison, F., Leach, C., Lucock, M., Mellor-Clark, J., Evans, C., et al. (2001). Service profiling and outcomes benchmarking using the CORE-OM:

Toward practice-based evidence in the psychological therapies. Journal of Consulting and Clinical Psychology, 69, 184-196. DOI: 10.1037/0022006X.69.2.184

Barkham, M., Gilbert, N., Connell, J., Marshall, C., \& Twigg, E. (2005a). Suitability and utility of the CORE-OM and CORE-A for assessing the severity of presenting problems in psychological therapy services based in primary and secondary care settings. British Journal of Psychiatry, 186, 239-246.

Barkham, M., Culverwell, A., Spindler, K., \& Twigg, E. (2005b). The CORE-OM in an older adult population: Psychometric status, acceptability and feasibility. Aging and Mental Health, 9, 235-245.

Barkham, M., Mellor-Clark, J., Connell, J., \& Cahill, J. (2006). A core approach to practice-based evidence: A brief history of the origins and applications of the COREOM and CORE System. Counselling and Psychotherapy Research, 6, 3-15.

Barkham, M., Mellor-Clark, J., Connell, J., Evans, C., Evans, R., \& Margison, F. (2010). Clinical Outcomes in Routine Evaluation (CORE) - The CORE measures and system: Measuring, monitoring and managing quality evaluation in the psychological therapies. In M. Barkham, G. E. Hardy, \& J. Mellor-Clark (Eds), Developing and delivering practice-based evidence: A guide for the psychological therapies (pp. 175-220). Chichester, UK: John Wiley \& Sons. 
Bedford, A., Watson, R., Lyne, J., Tibbles, J., Davies, F., \& Deary, I. J. (2010). Mokken scaling and principal components analyses of the CORE-OM in a large clinical sample. Clinical Psychology and Psychotherapy, 17, 51-62.

Bewick, B. M., Trusler, K., Mullin, T., Grant, S., \& Mothersole, G. (2006). Routine outcome measurement completion rates of the CORE-OM in primary care psychological therapies and counselling. Counselling and Psychotherapy Research, 6, 33-40.

Bjelland, I., Dahl, A. A., Haug, T. T., \& Neckelmann, D. (2002). The validity of the Hospital Anxiety and Depression Scale: An updated literature review. Journal of Psychosomatic Research, 52, 69-77.

Bohn, K., Doll, H. A., Cooper, Z., O’Connor, M., Palmer, R. L., \& Fairburn, C. G. (2008). The measurement of impairment due to eating disorder psychopathology. Behaviour Research and Therapy, 46(10), 1105-1110.

Bohn, K. \& Fairburn, C. G. (2008). The Clinical Impairment Assessment questionnaire (CIA). In C. G. Fairburn (Ed.), Cognitive behaviour therapy and eating disorders (pp. 315-317). New York: Guilford Press.

Connell, J., Barkham, M., \& Mellor-Clark, J. (2007). CORE-OM mental health norms of students attending university counselling services benchmarked against an agematched primary care sample. British Journal of Guidance Counselling, 35, 41-57.

Cooper, Z., \& Fairburn, C. (1987). The eating disorder examination: A semi-structured interview for the assessment of the specific psychopathology of eating disorders. International Journal of Eating Disorders, 6(1), 1-8. 
Crawford, J. R., Henry, J. D., Crombie, C., \& Taylor, E. P. (2001). Normative data for the HADS from a large non-clinical sample. British Journal of Clinical Psychology, $40,429-434$.

Elfström, M. L., Evans, C., Lundgren, J., Johansson, B., Hakeberg, M., \& Carlsson, S. G. (in press). Validation of the Swedish version of the Clinical Outcomes in Routine Evaluation Outcome Measure (CORE-OM). Clinical Psychology and Psychotherapy. DOI: 10.1002/cpp.1788.

Evans, C., Connell, J., Barkham, M., Margison, F., McGrath, G., Mellor-Clark, J., \& Audin, K. (2002). Towards a standardised brief outcome measure: Psychometric properties and utility of the CORE-OM. British Journal of Psychiatry, 180, 51-60.

Fairburn, C. G., \& Beglin, S. J. (1994). Assessment of eating disorders: Interview or self-report questionnaire? International Journal of Eating Disorders, 16, 363-370.

Fairburn, C. G., \& Cooper, Z. (1993). The Eating Disorder Examination (12 $2^{\text {th }}$ Ed.). In C. G. Fairburn \& G. T. Wilson (Eds.), Binge eating: Nature, assessment, and treatment (pp. 317-360). New York: Guilford Press.

Hoffart, A., Lysebo, H., Sommerfeldt, B., \& Rø, Ø. (2010). Change processes in residential cognitive therapy for bulimia nervosa. European Eating Disorders Review, 18, 367-375.

Jenkins, P. E., Hoste, R. R., Meyer, C., \& Blissett, J. M. (2011). Eating disorders and quality of life: A review of the literature. Clinical Psychology Review, 31, 113-121.

Killips, C., Cooper, M., Freire, E. S., \& McGinnis, S. (2012). Motivation as a predictor of outcomes in school-based humanistic counselling. Counselling and Psychotherapy Research: Linking research with practice, 12(2), 93-99. 
Luce, K. H., \& Crowther, J. H. (1999). The reliability of the eating disorder examination-Self-report questionnaire version (EDE-Q). International Journal of Eating Disorders, 25, 349-351.

Lyne, K. J., Barrett, P., Evans, C., \& Barkham, M. (2006). Dimensions of variation on the CORE-OM. British Journal of Clinical Psychology, 45, 185-203.

Mykletun, A., Stordal, E., \& Dahl, A. A. (2001). Hospital Anxiety and Depression (HAD) scale: Factor structure, item analyses and internal consistence in a large population. The British Journal of Psychiatry, 179, 540-544.

Rosen, J. C., Vara, L., Wendt, S., \& Leitenberg, H. (1990). Validity studies of the eating disorder examination. International Journal of Eating Disorders, 9, 519-528.

Sheffield, J., \& Lemétayer, J. (in press). Factors associated with the software development agility of successful projects. International Journal of Project Management, DOI: http://dx.doi.org/10.1016/j.ijproman.2012.09.011.

Simpson, S. G., \& Slowey, L. (2011). Video therapy for atypical eating disorder and obesity: A case study. Clinical Practice in Epidemiology and Mental Health, 4, 3843.

Snaith, R. P. (2003). The Hospital Anxiety And Depression Scale. Health and Quality of Life Outcomes, 1:29.

Spinhoven, Ph., Ormel, J., Sloekers, P. P. A., Kempen, G. I. J. M., Speckens, A. E. M., \& Van Hemert, A. M. (1997). A validation study of the Hospital Anxiety and Depression Scale (HADS) in different groups of Dutch subjects. Psychological Medicine, 27, 363-370.

Stevens, J. P. (2002). Applied multivariate statistics for the social sciences $\left(4^{\text {th }} \mathrm{Ed}\right.$.). Mahwah, NJ: Lawrence Erlbaum Associates. 
Traviss, G. D., Heywood-Everett, S., \& Hill, A. J. (2011). Guided self-help for disordered eating: A randomised control trial. Behaviour Research and Therapy, 49, 25-31.

Uji, M., Sakamoto, A., Adachi, K., \& Kitamura, T. (2012). Psychometric properties of the Japanese version of the Clinical Outcomes in Routine Evaluation-Outcome Measure. Comprehensive Psychiatry, 53, 600-608. DOI:

10.1016/j.comppsych.2011.09.006.

Wilson, G. T. \& Smith, D. (1989). Assessment of bulimia nervosa: An evaluation of the Eating Disorders Examination. International Journal of Eating Disorders, 8, 173179.

Wright, F., Bewick, B. M., Barkham, M., House, A. O., \& Hill, A. J. (2009). Cooccurrence of self-reported disordered eating and self-harm in UK university students. British Journal of Clinical Psychology, 48, 397-410.

Zigmond, A. S., \& Snaith, R. P. (1983). The hospital anxiety and depression scale. Acta Psychiatrica Scandanavica, 67, 361-370. 
Table 1. Gender comparison in the sample on the CORE-OM subscales

\begin{tabular}{llllll}
\hline CORE-OM & Women $(n=$ & Men $(n=$ & Mean & $95 \%$ CIs & $P$ \\
subscale & $329-332)$ & $22)$ & difference & & \\
\hline Well-being & 2.66 & 2.52 & 0.14 & $-0.29,0.57$ & 0.508 \\
Problems & 2.42 & 2.44 & -.017 & $-0.47,0.44$ & 0.937 \\
Functioning & 2.09 & 2.11 & -.021 & $-0.40,0.36$ & 0.907 \\
Risk & 0.68 & 0.92 & -0.23 & $-0.65,0.18$ & 0.254 \\
Total & 1.99 & 2.10 & -0.11 & $-.040,0.38$ & 0.554 \\
Total minus risk & 2.30 & 2.31 & 0.01 & $-0.39,0.39$ & 0.996 \\
\hline
\end{tabular}


Table 2. Pattern matrix for the current sample

\begin{tabular}{|c|c|c|c|c|c|}
\hline \multirow[t]{2}{*}{ Item } & \multirow[t]{2}{*}{ Description } & \multirow[t]{2}{*}{ Domain } & \multicolumn{3}{|c|}{ Component } \\
\hline & & & 1 & 2 & 3 \\
\hline 1 & I have felt terribly alone and isolated & $\mathrm{F}$ & .530 & .258 & .016 \\
\hline 2 & I have felt tense, anxious, or nervous & $\mathrm{P}$ & .719 & -.076 & -.160 \\
\hline 3 & $\begin{array}{l}\text { I have felt I have someone to turn to for } \\
\text { support when needed }\end{array}$ & $\mathrm{F}$ & -.393 & .779 & .165 \\
\hline 4 & I have felt OK about myself & $\mathrm{W}$ & .233 & .554 & -.046 \\
\hline 5 & $\begin{array}{l}\text { I have felt totally lacking in energy and } \\
\text { enthusiasm }\end{array}$ & $\mathrm{P}$ & .546 & .126 & -.215 \\
\hline 6 & I have been physically violent to others & $\mathrm{R}$ & -.257 & -.156 & .727 \\
\hline 7 & I have felt able to cope when things go wrong & $\mathrm{F}$ & .306 & .406 & -.033 \\
\hline 8 & $\begin{array}{l}\text { I have been troubled by aches, pains or other } \\
\text { physical problems }\end{array}$ & $\mathrm{P}$ & .685 & -.246 & -.107 \\
\hline 9 & I have thought of hurting myself & $\mathrm{R}$ & .152 & .239 & .527 \\
\hline 10 & Talking to people has felt too much for me & $\mathrm{F}$ & .496 & .123 & .099 \\
\hline 11 & $\begin{array}{l}\text { Tension and anxiety have prevented me doing } \\
\text { important things }\end{array}$ & $\mathrm{P}$ & .658 & .010 & .067 \\
\hline 12 & I have been happy with the things I have done & $\mathrm{F}$ & .033 & .794 & -.203 \\
\hline 13 & $\begin{array}{l}\text { I have been disturbed by unwanted thoughts } \\
\text { and feelings }\end{array}$ & $\mathrm{P}$ & .680 & -.109 & .074 \\
\hline 14 & I have felt like crying & $\mathrm{W}$ & .646 & .067 & -.044 \\
\hline 15 & I have felt panic or terror & $\mathrm{P}$ & .754 & -.279 & -.049 \\
\hline 16 & I made plans to end my life & $\mathrm{R}$ & .095 & .152 & .503 \\
\hline
\end{tabular}




\begin{tabular}{|c|c|c|c|c|c|}
\hline 17 & I have felt overwhelmed by my problems & $\mathrm{W}$ & .747 & .042 & -.011 \\
\hline 18 & $\begin{array}{l}\text { I have had difficulty getting to sleep or staying } \\
\text { asleep }\end{array}$ & $\mathrm{P}$ & 639 & -.060 & -.052 \\
\hline 19 & I have felt warmth or affection for someone & $\mathrm{F}$ & -.371 & .743 & .094 \\
\hline 20 & $\begin{array}{l}\text { My problems have been impossible to put to } \\
\text { one side }\end{array}$ & $\mathrm{P}$ & .838 & -.069 & -.144 \\
\hline 21 & I have been able to do most things I needed to & $\mathrm{F}$ & .125 & .486 & -.023 \\
\hline 22 & I have threatened or intimidated another person & $\mathrm{R}$ & -.169 & -.171 & .709 \\
\hline 23 & I have felt despairing or hopeless & $\mathrm{P}$ & .664 & .154 & .098 \\
\hline 24 & I have thought it would be better if I were dead & $\mathrm{R}$ & .213 & .231 & .506 \\
\hline 25 & I have felt criticised by other people & $\mathrm{F}$ & .384 & .122 & .181 \\
\hline 26 & I have thought I have no friends & $\mathrm{F}$ & .119 & .333 & .273 \\
\hline 27 & I have felt unhappy & $\mathrm{P}$ & .576 & .316 & -.022 \\
\hline 28 & $\begin{array}{l}\text { Unwanted images or memories have been } \\
\text { distressing me }\end{array}$ & $\mathrm{P}$ & .623 & -.150 & .171 \\
\hline 29 & I have been irritable when with other people & $\mathrm{F}$ & .525 & -.002 & .152 \\
\hline 30 & $\begin{array}{l}\text { I have thought I am to blame for my problems } \\
\text { and difficulties }\end{array}$ & $\mathrm{P}$ & .534 & .123 & -.039 \\
\hline 31 & I have felt optimistic about my future & $\mathrm{W}$ & .058 & .779 & -.218 \\
\hline 32 & I have achieved the things I wanted to & $\mathrm{F}$ & -.001 & .774 & -.178 \\
\hline 33 & $\begin{array}{l}\text { I have felt humiliated or shamed by other } \\
\text { people }\end{array}$ & $\mathrm{F}$ & .374 & -.010 & .343 \\
\hline 34 & $\begin{array}{l}\text { I have hurt myself physically or taken } \\
\text { dangerous risks with my health }\end{array}$ & $\mathrm{R}$ & .244 & -.071 & .548 \\
\hline
\end{tabular}


Table 3. Internal consistency of the CORE-OM subscales $(n=353-357)$

\begin{tabular}{lll}
\hline Subscale & Mean (SD) & Cronbach's $\alpha$ \\
\hline Well-being & $2.65(0.89)$ & .75 \\
Problems & $2.41(0.86)$ & .87 \\
Functioning & $2.09(0.78)$ & .85 \\
Risk & $0.70(0.77)$ & .77 \\
Total & $2.03(0.78)$ & .94 \\
Total minus Risk & $2.31(0.76)$ & .93 \\
\hline
\end{tabular}


Table 4. Spearman's correlations $(r)$ with measures in the current sample Measure

\begin{tabular}{llllll}
\hline \multicolumn{7}{c}{ Measure } & & & \\
\hline CORE Subscale & $n$ & EDE Global & CIA Total & HADS-D & HADS-A \\
Well-being & 343 & .47 & .63 & .57 & .49 \\
Problems & 344 & .51 & .69 & .62 & .63 \\
Functioning & 342 & .47 & .62 & .66 & .52 \\
Total & 341 & .53 & .68 & .67 & .59 \\
Total minus risk & 342 & .53 & .69 & .67 & .60 \\
Risk & 344 & .39 & .49 & .53 & .43 \\
\hline
\end{tabular}

Note: All significant at $p<.01$ 
Table 5. Diagnostic comparison (diagnosis of an ED vs. no diagnosis) on the COREOM subscales

\begin{tabular}{llllll}
\hline CORE-OM & ED $(n=324-$ & Non-ED $(n$ & Mean & $95 \%$ CIs & $P$ \\
subscale & $326)$ & $=28)$ & Difference & & \\
\hline Well-being & 2.70 & 2.15 & -0.55 & $-0.97,-0.12$ & .010 \\
Problems & 2.47 & 1.88 & -0.58 & $-0.98,-0.19$ & .003 \\
Functioning & 2.12 & 1.74 & -0.38 & $-0.72,-0.05$ & .016 \\
Risk & 0.73 & 0.26 & -0.47 & $-0.71,-0.24$ & $<.001$ \\
Total & 2.05 & 1.10 & -0.96 & $-1.54,-0.38$ & .003 \\
Total minus risk & 2.35 & 1.87 & -0.49 & $-0.84,-0.14$ & .004 \\
\hline
\end{tabular}


Figure 1. Scree plot for the sample 